\title{
The Efficacy of Autologous Nanofat Injection in the Treatment of Infraorbital Dark Colouration
}

\author{
EHAB Z. AZZAM, M.D.; HASSAN M. KHOLOSY, M.D. and MOHAMED H. ABOUARAB, M.D.
}

The Department of Plastic Surgery, Faculty of Medicine, Alexandria University, Egypt

\begin{abstract}
Background: Periorbital hyperpigmentation is a common worldwide problem, which makes a person appear tired, sad, and aged. A number of factors can cause dark circles around the eyes including excessive pigmentation, thin and translucent lower eyelid skin overlying the orbicularis oculi muscle, and shadowing due to skin laxity and tear trough. Although a number of treatment options are available, autologous fat transplantation is an effective method for the treatment of lower lid dark circles, but irregularities caused by leaving visible lumps of the fat can occur. Mechanical emulsification of harvested fat achieves much more finer fat particles than micro-fat called nano-fat which acts primarily by the plenty the active transplanted stem cells the purpose of this study is to evaluate the effectiveness of the nanofat grafting technique in correcting infraorbital dark circles.
\end{abstract}

Pateints and Methods: Nanofat grafting was performed in 10 female patients for dark lower eyelids. The grafts were injected into intra-dermal and sub-dermal layers using sharp $27 \mathrm{G}$ needle and were harvested from different sites according to the ease of accessibility and to improve the patient's body contours. The mean follow-up period was 4.6 months, ranging from 2 to 8 months. All patients were clinically evaluated using standardized serial digital photographs by two plastic surgeons, who were blinded to the type of procedure performed at each of the follow-up visits.

Results: In this study, there was significant improvement of the peri-ocular dark halos in 5 cases $(50 \%)$, moderate improvement was encountered in 2 cases (20\%), 2 cases (20\%) showed mild improvement and no improvement in one case $(10 \%)$. As regards patient satisfaction, 8 cases $(80 \%)$ were satisfied with the final result, while 2 patients $(20 \%)$ were not satisfied. Post-operative edema and ecchymosis were minimal in 5 cases (50\%) and mild in 5 cases (50\%). No cases were presented with either post injection infection or lumps and contour irregularities during the follow-up period.

Conclusion: In conclusion, nano fat injections for the treatment of infra orbital dark circles is a simple, cost effective procedure. In addition, nanofat grafting technique provided a significant improvement in skin quality. Our results suggest that the stem cell activity of the nanofat grafting technique has great potential as a treatment modality for dark circles as well as for skin rejuvenation in general.

Key Words: Nanofat injection - Infraorbital - Dark colouration.

\section{INTRODUCTION}

The eyes not only convey the full range of human emotion but also have a significant impact on how one is perceived in terms of health and beauty. Besides the common alterations related to the intrinsic and extrinsic aging processes such as the appearance of fine lines, loose skin, and excess fat deposition, there is one that affects individuals of any age, both genders and all races: The socalled "dark circles under the eyes" or Periorbital hyperpigmentation (POH). Unfortunately, this manifestation can worsen with time because of age-related skin sagging, loss of subcutaneous fat and hollowness of the periorbital area [1].

Infraorbital dark circles are defined as bilateral, round, homogeneous pigment macules on the infraorbital regions which interferes with the face appearance, giving the patient a tired, aged, sad, or hangover look. Although considered a phenomenon within the limit of physiology, patients, especially women, are really bothered and concerned about it, even relating the presence of dark circles with significant impairment on their quality of life that necessitate treatment [2].

Dark circles around the eye are caused by various overlapping endogenous and exogenous factors. One cause is excessive pigmentation due to either congenital or acquired dermal melanocytosis [3]. Another common cause of dark circle is a thin, translucent lower eyelid skin overlying the orbicularis oculi muscle which lies right beneath the skin, with little or no subcutaneous fat, and the darkness may be due to the visible prominence of the subcutaneous vascular plexus or vasculature contained within the muscle [4]. Shadowing due to skin laxity and tear trough is another cause of infraorbital dark circle [5]. 
The therapeutic approach is frequently lengthy, so, patients and physicians must together plan the appropriate course of treatment to achieve desired results. Treatment options for dark circles vary depending on the primary causative factor, among the available alternatives to improve dark circles due to excessive hyperpigmentaton are: Bleaching creams, topical retinoic acid, chemical peels, facial makeup preparations and, recently, laser therapy $[6,7]$.

For infraorbital dark circles due to thin and translucent lower eyelid skin overlying the orbicularis oculi muscle, the therapeutic modality is to restore the volume underneath the eyelid. One of the methods of restoration is autologous fat transplantation, which has long been used for soft-tissue augmentation and is known to be effective, especially for patients with the vascular type of dark circle, as injecting fat between the skin and muscle can be expected to act as a barrier that prevents visualization of hypervascularity within the muscle, moreover, autologous fat is completely biocompatible, available, and is therefore the safest choice for altering facial volume or contours [8,9].

One of possible complications of autologous fat grafting is the irregularity caused by visible lumps. In 2013, Tonnard et al., reported on the efficiency and safety of treating skin aging with nanofat, which in contrast to the traditional fat grafting method, which acts primarily by producing a physical volume effect, nanofat grafting may act primarily by the activity of transplanted Nanofatderived Stem Cells (NFSCs) in an emulsified fat suspension to promote skin rejuvenation [10].

NFSCs belong to a subcategory of Adiposederived Stem Cells (ASCs), which are known to participate in repair after injury, and their functions in skin rejuvenation have been described [11].

This study was conducted to evaluate the efficacy of autologous nanofat injection in treatment of dark circles under the eyes.

\section{PATIENTS AND METHODS}

Ten female patients with infraorbital dark of the skin aged 19 to 50 years old (mean, 30 years old) were included in this study. They were admitted for other Plastic Surgery Operations and nano fat grafting for their dark lower eyelids was performed in the same setting of these operations from March 2016 to March 2017. All patients were admitted to the Plastic Surgery Department at Alexandria Main University Hospital for abdominoplasty in 4 patients, reduction mammoplasty in 2 patients, arm liposuction in 2 patients, pan-facial lipofilling in one patient and MACS lift in one patient. The mean follow-up period was 4.6 months, ranging from 2 to 8 months.

\section{Operative technique:}

The harvesting sites were chosen for ease of accessibility and to improve the patient's body contours. Lower abdomen (4 cases), medial thigh ( 2 cases), buttock ( 2 cases) and the arm ( 2 cases) were utilized for fat harvesting.

Under general anaesthesia and with complete aseptic conditions, infiltration of the donor site with a modified Klein solution (lidocaine 800 $\mathrm{mg} / \mathrm{liter}$ and adrenaline 1:1,000,000) was done.

Through 3-mm incisions made by 11 blade scalpel, fat was harvested with a multiport $3 \mathrm{~mm}$ cannula with sharp side holes of $1 \mathrm{~mm}$ in diameter attached to a Luer-Lock syringe Fig. (1), the cannula is pushed through the harvest site and then the plunger of the syringe was pulled back to create a gentle negative pressure allowing parcels of fat to move through the cannula and Luer-Lock aperture into the barrel of the syringe. When filled, the syringe was disconnected from the cannula and replaced with a plug that seals the Luer-Lock end of the syringe. This was followed with saline rinsing and filtering of the lipoaspirate.

Mechanical emulsification was then done by shifting the fat between two 10-cc syringes connected to each other by a 3 way adapter. After 2030 passes, the fat changed into an emulsion. At the end of the fragmentation process, the fat became liquid with a whitish appearance Fig. (2).

After this emulsification process, the fatty liquid was again filtered over the sterile nylon cloth Fig. (3) and the effluent was collected in a sterile recipient to remove the connective tissue remnants that would block the fine needles. This effluent is called "Nano fat." Fig. (4).

A 27-gauge needle was mounted on the syringe for superficial intradermal and subdermal injection. In this study, two types of needles were used for injection, the traditional $27 \mathrm{G}$ needle mounted on $1 \mathrm{ml}$ syringe ( 5 cases) and the dental $27 \mathrm{G}$ needle mounted on the metal dental syringe ( 5 cases) Fig. (5).

Injection was performed until a yellowish discoloration of the skin showed up Fig. (6). Gentle digital spreading of the injected nanofat in all directions was done followed by fucidic acid ointment and cold compresses application immediately after injection in all cases. 


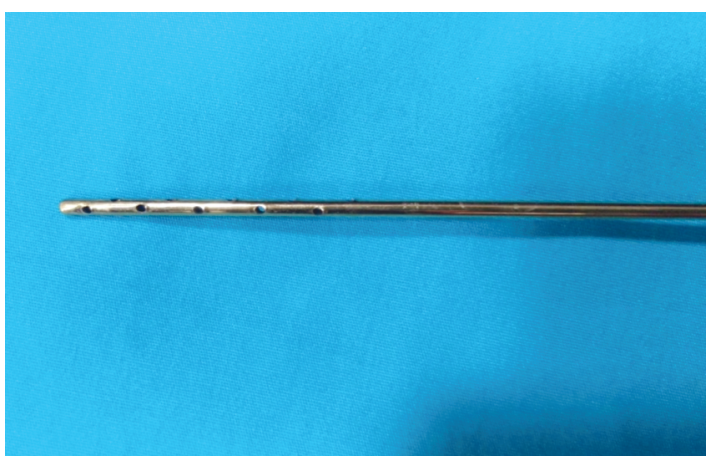

Fig. (1): $3 \mathrm{ml}$ harvesting cannula with $1 \mathrm{ml}$ diameter sharp side holes.

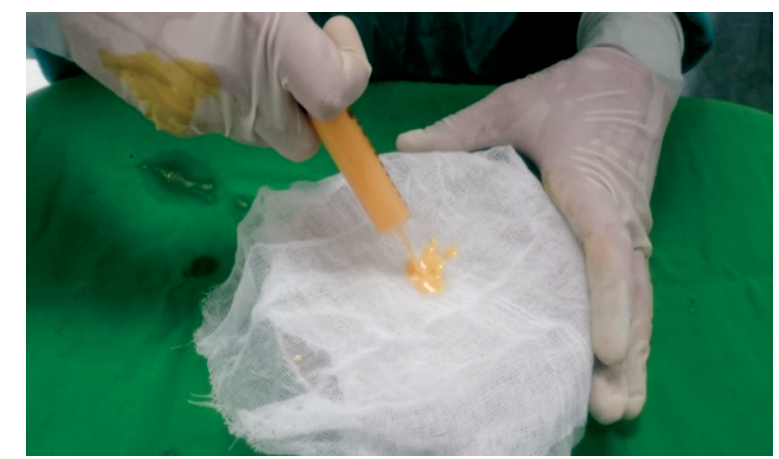

Fig. (3): Filtration of fat using sterile nylone gouze after emulsification.

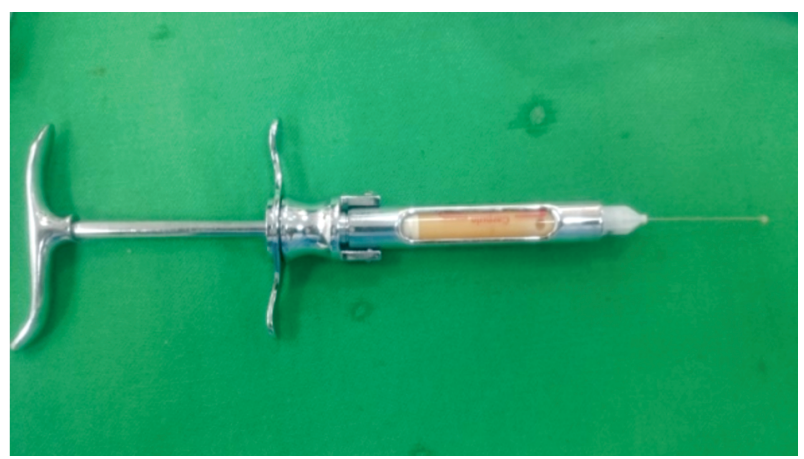

Fig. (5): Dental syringe and needle loaded with nanofat ready for injection.

All patients were instructed to gently apply fucidic acid ointment on the injected area three times daily for five days as well as cold compresses application for fifteen minutes every hour for the first post-operative day.

Standardized coloured digital photographs were taken with the same camera and illumination source and from the same angle at each of the follow-up visits (1, 3, 6 and 8 months).

\section{Assessment of outcomes:}

All patients were clinically evaluated using these serial photographs by two plastic surgeons who were blinded to the type of procedure per-

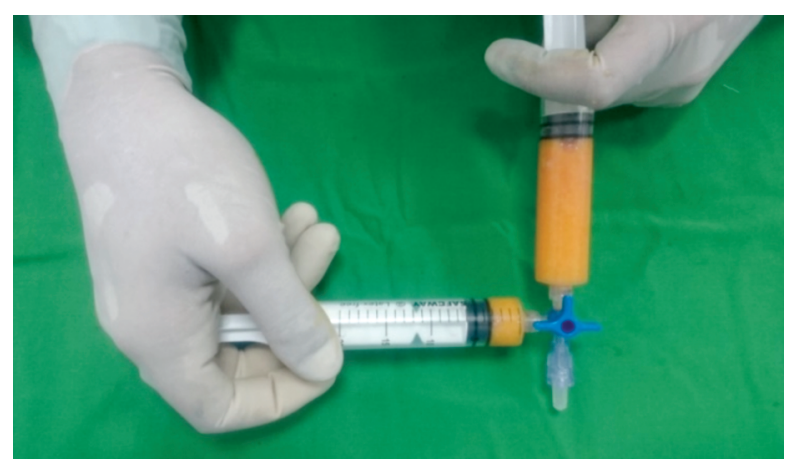

Fig. (2): Fragmentation process by shifting the fat between two 10 -cc syringes connected to each other by a 3 way adapter.

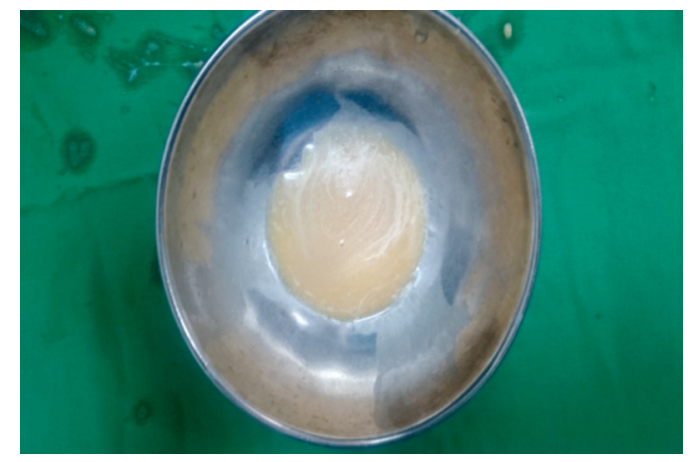

Fig. (4): Nanofat ready for injection.

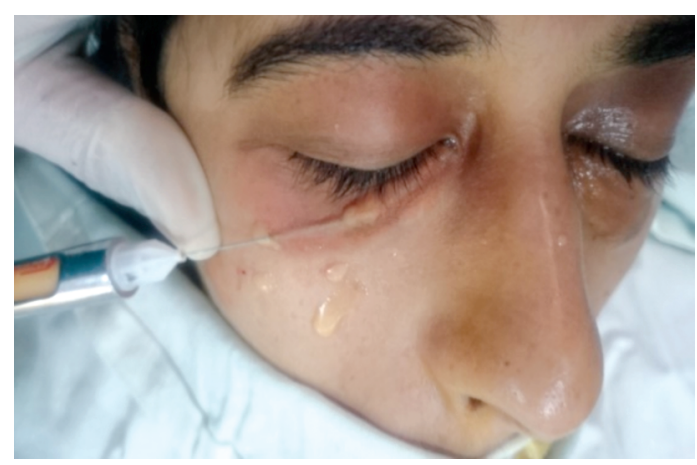

Fig. (6): Intradermal nanofat injection using $27 \mathrm{G}$ dental needle. The end point which is yellowish discoloration of the skin showed up.

formed using the following four-point scale [12] based on colour improvement:

$0=$ Poor result. (Same colour of the dark halos as pre-operative picture).

$1=$ Mild improvement. (Improved colour but still close to the pre-operative picture).

$2=$ Moderate improvement. (Improved colour but still not like the surrounding normal skin).

3 = Significant improvement. (Complete resolution of dark halos like the surrounding skin).

Patients were also asked about their own level of satisfaction either they were satisfied about the final result or not. Post-operative complications, including infection, ecchymosis, pain, edema, erythema and contour irregularities were evaluated during the follow-up period. 


\section{RESULTS}

Demographic criteria of the patients and clinical outcomes are shown in Table (1).

Ten female patients were treated with autologous intra and subdermal injection of nano fat for their infraorbital dark circles due to various causes. The mean age of the studied patients was 33.7 years old; ranging from 19 years old to 50 years old. The majority of patients were between 30 to 40 years of age $(50 \%)$. The amount of nano fat injected ranged from $3.2 \mathrm{ml}$ to $4.2 \mathrm{ml}$ for each patient with average $3.71 \mathrm{ml}$.

In the current study the traditional 27 Gauge needle mounted on $1 \mathrm{ml}$ syringe (insulin syringe) was used for injection in 5 cases $(50 \%)$, and the dental needle mounted on the metal dental syringe was used in the other 5 cases (50\%). In all patients, nanofat grafting was done in association with other plastic surgery operations as follow: 4 cases (40\%)
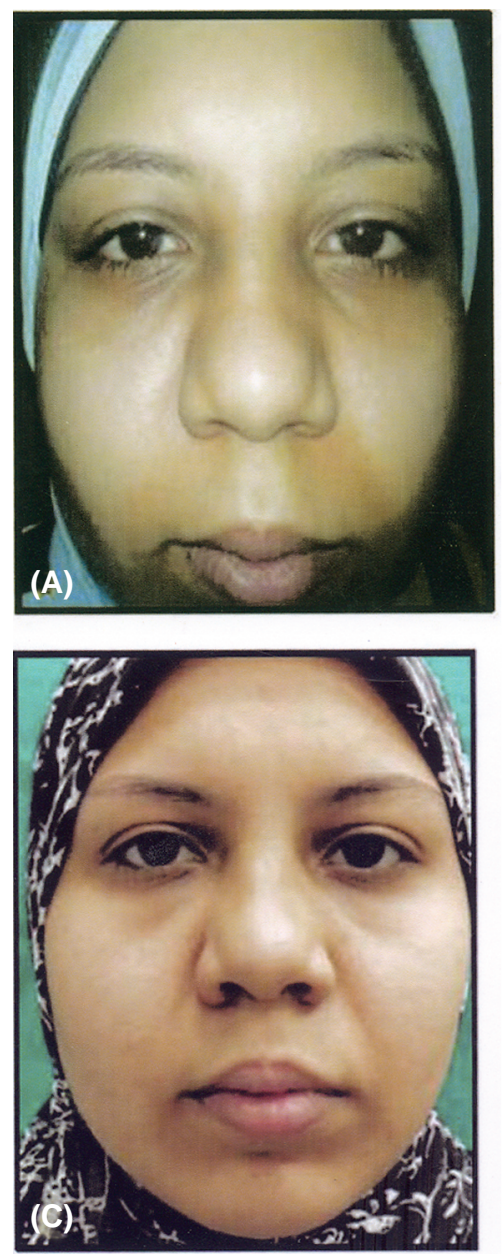

with abdominoplasty, 2 cases (20\%) with reduction mammoplasty, 2 cases (20\%) with arm liposuction, 1 case $(10 \%)$ with MACS lift and 1 case $(10 \%)$ with panfacial lipofilling. Fat was harvested from different sites as follows, the lower abdomen in 4 cases $(40 \%)$, the buttock in 2 cases $(20 \%)$, medial thigh in 2 cases $(20 \%)$ and arm in 2 cases $(20 \%)$. post-operative edema and ecchymosis were minimal in 5 cases $(50 \%)$. And mild in 5 cases $(50 \%)$.

In this study, there was significant improvement of the peri-ocular dark halos in 5 cases $(50 \%)$, moderate improvement was encountered in 2 cases (20\%), 2 cases (20\%) showed mild improvement and no improvement in one case (10\%). According to the two evaluating surgeons who were blind about the used technique, there was a good agreement between them about the clinical outcome. As regards patient satisfaction, 8 cases $(80 \%)$ were satisfied with the final result, while 2 patients $(20 \%)$ were not satisfied. Figs. (7-9) show some results of this technique.
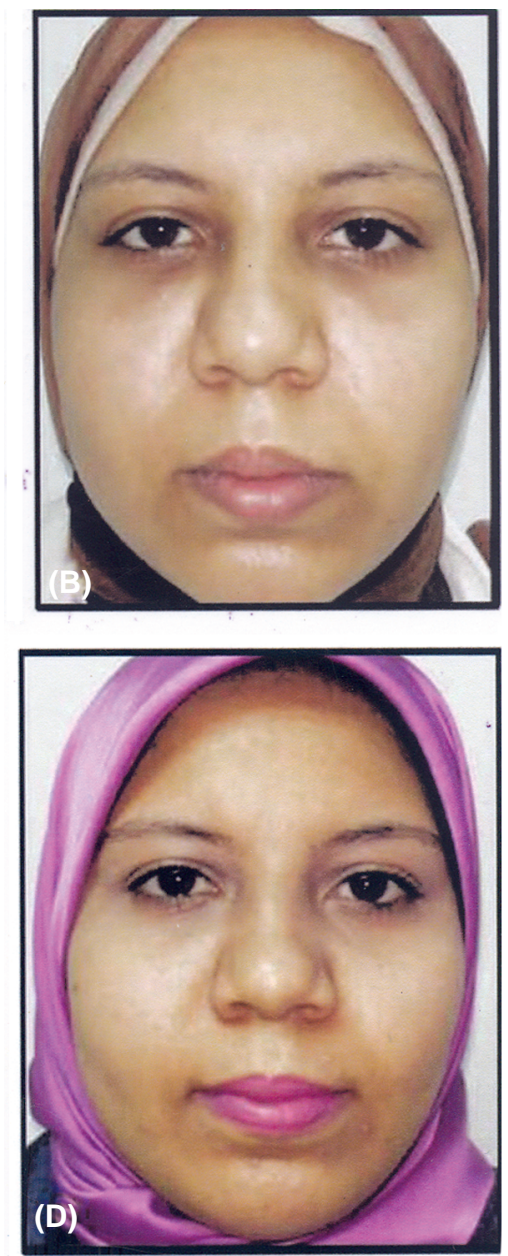

Fig. (7): (A) Pre-op. pic. of 28 years old patient with dark halos treated with $1.8 \mathrm{cc}$ nanofat intradermal and subdermal injection for each side. (B) 1 month post-op. picture shawing slight erythema. (C) 3 months post-op. picture with marked dark halos improvement and improved skin texture. (D) 8 months pic. Postop. with significant dark halos improvement. 

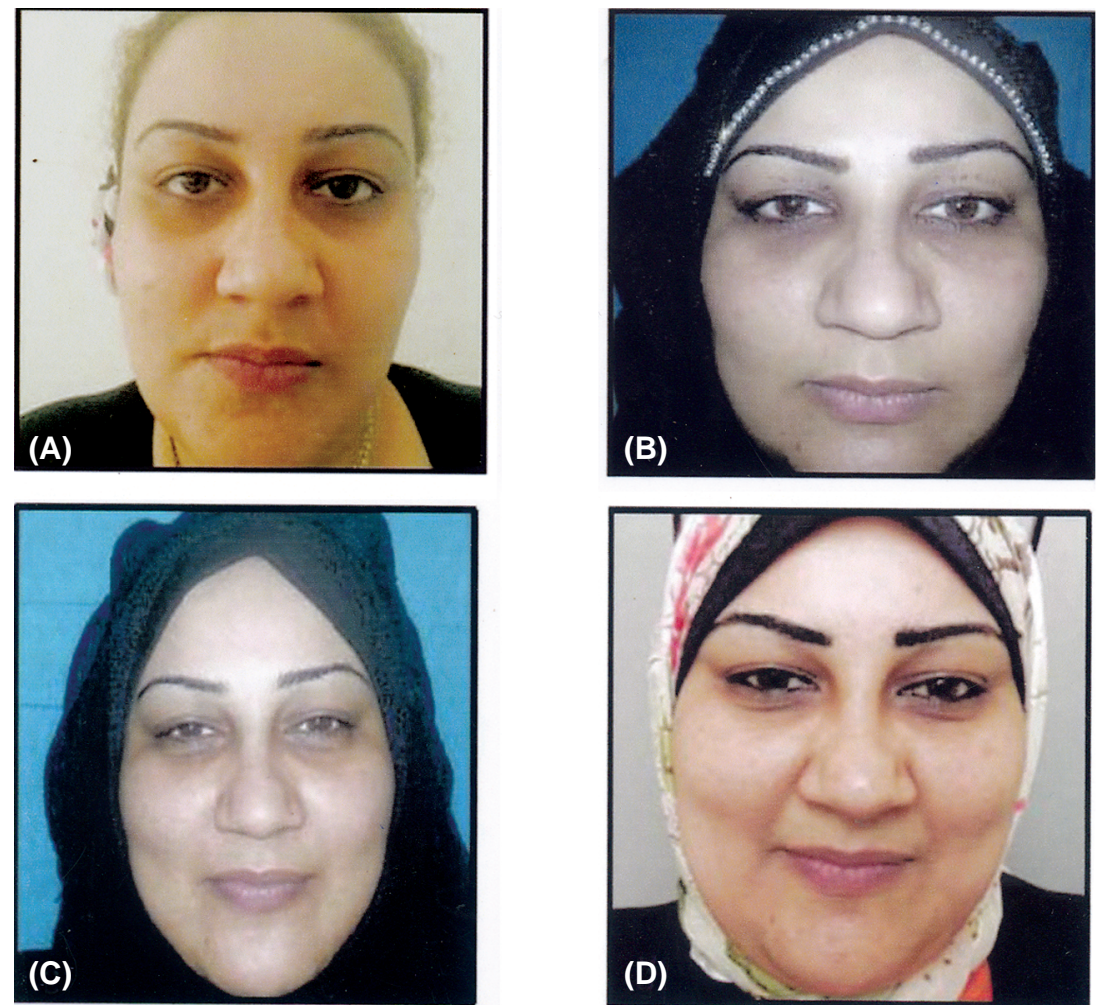

Fig. (8): (A) Pre-operative picture of 31 years old patient with peri-ocular dark halos, $1.9 \mathrm{cc}$ intra and subdemal nanofat for each side. (B) 1 month post-operative showing erthyma. (C) 3 months post-operative shawing fading of erthyma and improvement of dark halos. (D) 6 months post-op. picture with significant improvement of dark hallos.
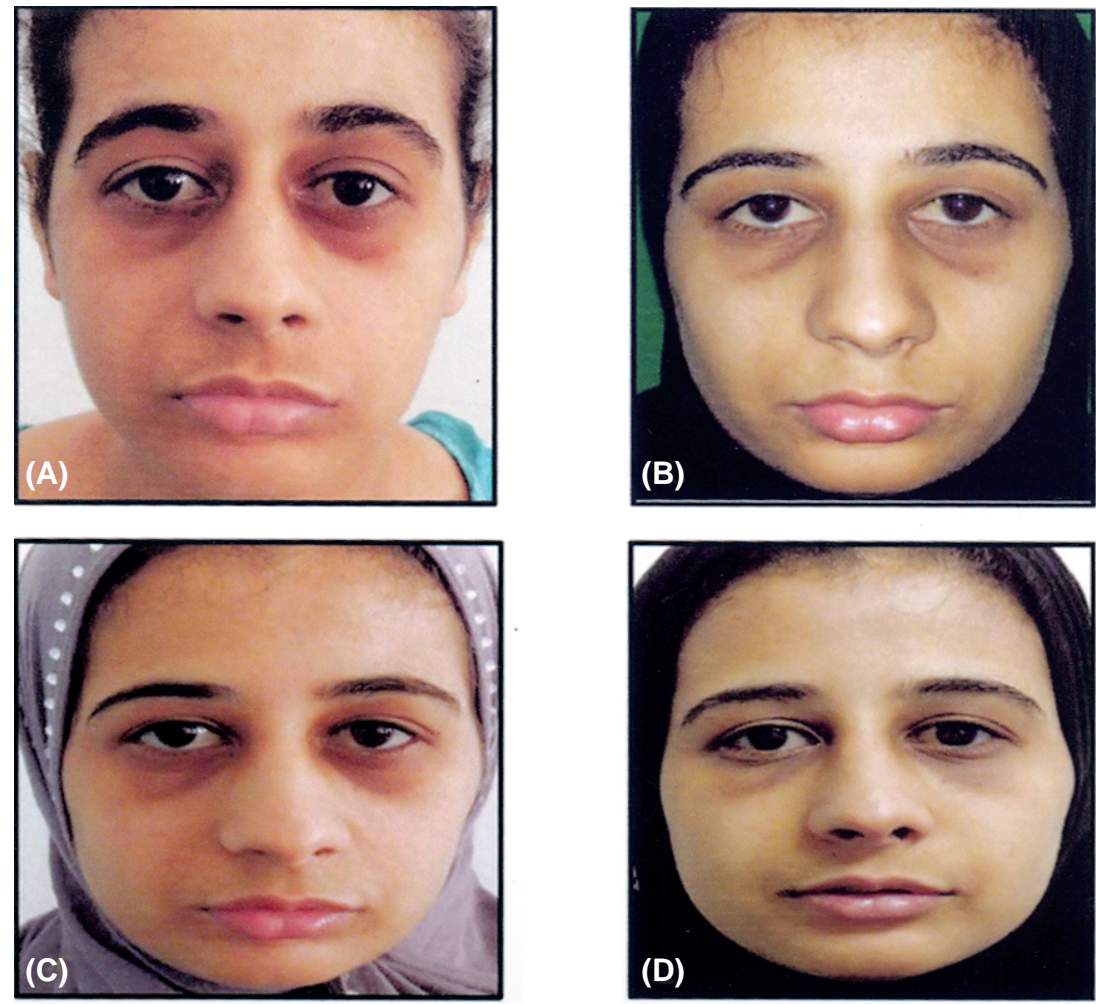

Fig. (9): (A) Pre-op. pic. of 19 years old patient with peri-ocular dark halos treated with $1.6 \mathrm{cc}$ nanofat injection for each side. (B) 1 month post-op. pic. Dark halos still present with slight erythema. (C) 3 months post operative. (D) 5 months with moderate improvement of dark halo is noted. 
Table (1): Demographic criteria of the patients and clinical outcomes.

\begin{tabular}{|c|c|c|c|c|c|c|c|c|c|c|}
\hline $\mathrm{pt}$ & Sex & $\begin{array}{l}\text { Age } \\
(y s)\end{array}$ & $\begin{array}{l}\text { Donor } \\
\text { site }\end{array}$ & Type of needle & $\begin{array}{l}\text { Main surgical } \\
\text { procedure }\end{array}$ & $\begin{array}{c}\text { The amount of } \\
\text { Nanofat } \\
\text { injected }(\mathrm{ml})\end{array}$ & $\begin{array}{l}\text { Follow-up } \\
\text { period } \\
\text { (month) }\end{array}$ & $\begin{array}{l}\text { Post operative } \\
\text { odema } \\
\text { and ecchymosis }\end{array}$ & $\begin{array}{c}\text { Clinical } \\
\text { improvement }\end{array}$ & $\begin{array}{c}\text { Patient } \\
\text { satisfaction }\end{array}$ \\
\hline 1 & Female & 31 & $\begin{array}{l}\text { Lower } \\
\text { abdomen }\end{array}$ & $\begin{array}{l}27 \text { Gauge needle } \\
\text { (insulin syringe) }\end{array}$ & Abdominoplasty & 3.8 & 6 & Mild & $\begin{array}{l}\text { Significant } \\
\text { improvment }\end{array}$ & Satisfied \\
\hline 2 & Female & 19 & $\begin{array}{l}\text { Medial } \\
\text { thigh }\end{array}$ & $\begin{array}{l}27 \text { Gauge needle } \\
\text { (insulin syringe) }\end{array}$ & Breast reduction & 3.2 & 5 & Mild & $\begin{array}{l}\text { Moderate } \\
\text { improvment }\end{array}$ & Satisfied \\
\hline 3 & Female & 38 & Buttock & $\begin{array}{l}27 \text { Gauge needle } \\
\text { (insulin syringe) }\end{array}$ & $\begin{array}{l}\text { Pan-facial } \\
\text { lipofilling }\end{array}$ & 3.4 & 2 & Mild & $\begin{array}{l}\text { Moderate } \\
\text { improvment }\end{array}$ & Satisfied \\
\hline 4 & Female & 42 & $\begin{array}{l}\text { Lower } \\
\text { abdomen }\end{array}$ & $\begin{array}{l}27 \text { Gauge needle } \\
\text { (insulin syringe) }\end{array}$ & Abdominoplasty & 3.2 & 4 & Mild & $\begin{array}{l}\text { No } \\
\text { improvement }\end{array}$ & $\begin{array}{l}\text { Not } \\
\text { satisfied }\end{array}$ \\
\hline 5 & Female & 36 & $\begin{array}{l}\text { Lower } \\
\text { abdomen }\end{array}$ & $\begin{array}{l}27 \text { Gauge needle } \\
\text { (insulin syringe) }\end{array}$ & Abdominoplasty & 3.7 & 6 & Minimal & $\begin{array}{l}\text { Significant } \\
\text { improvment }\end{array}$ & Satisfied \\
\hline 6 & Female & 50 & $\begin{array}{l}\text { Medial } \\
\text { thigh }\end{array}$ & $\begin{array}{l}27 \text { Gauge needle } \\
\text { (dental syringe) }\end{array}$ & MACS lift & 4 & 7 & Mild & $\begin{array}{l}\text { Significant } \\
\text { improvment }\end{array}$ & Satisfied \\
\hline 7 & Female & 34 & Arm & $\begin{array}{l}27 \text { Gauge needle } \\
\text { (dental syringe) }\end{array}$ & Arm liposuction & 3.5 & 3 & Minimal & $\begin{array}{l}\text { Mild } \\
\text { improvment }\end{array}$ & $\begin{array}{l}\text { Not } \\
\text { satisfied }\end{array}$ \\
\hline 8 & Female & 37 & $\begin{array}{l}\text { Lower } \\
\text { abdomen }\end{array}$ & $\begin{array}{l}27 \text { Gauge needle } \\
\text { (dental syringe) }\end{array}$ & Abdominoplasty & 4.2 & 2 & Minimal & $\begin{array}{l}\text { Significant } \\
\text { improvment }\end{array}$ & Satisfied \\
\hline 9 & Female & 28 & Buttock & $\begin{array}{l}27 \text { Gauge needle } \\
\text { (dental syringe) }\end{array}$ & Breast reduction & 3.6 & 8 & Minimal & $\begin{array}{l}\text { Significant } \\
\text { improvment }\end{array}$ & Satisfied \\
\hline 10 & Female & 24 & Arm & $\begin{array}{l}27 \text { Gauge needle } \\
\text { (dental syringe) }\end{array}$ & Arm liposuction & 3.8 & 6 & Minimal & $\begin{array}{l}\text { Mild } \\
\text { improvment }\end{array}$ & Satisfied \\
\hline
\end{tabular}

\section{DISCUSSION}

Infraorbital dark circles affect people of both sexes, all races, and a wide range of ages. Although dark circles are neither health threatening nor associated with significant morbidity, yet, they cause considerable aesthetic concern and negatively impacts emotional well-being. Infraorbital dark circles are thought to have a multifactorial aetiology, including excessive skin pigmentation, thin and translucent lower eyelid skin overlying the orbicularis oculi muscle, and shadowing due to skin laxity and tear trough. Despite the frequency with which it occurs, little has been written in the scientific literature on the treatment of infraorbital dark circles [3].

The most appropriate treatment modality of the dark circle differs depending on the main causative factor. Topical skin lightening agents used for hyperpigmentation include hydroquinone, retinoic acid, mequinol, azelaic acid, and corticosteroids. Various combinations of these topical agents have been used to increase their efficacy while reducing side effects [13].

Chemical peeling, a process of removing the epidermis or upper dermis with chemical agents, is another option for patients with hyperpigmentation [14]. Vavouli et al., [15] used lactic acid 15\% in treating periorbital hyperpigmentation in combination with Trichloroacetic Acid (TCA) $3.75 \%$ and it was found that almost all the patients showed significant improvement. The most disturbing side effect of chemical peels was post-inflammatory hyperpigmentation. This may be minimized with the help of priming agents, such as hydroquinone and tretinoin.

Lasers are also appropriate options, not only for hyperpigmentation but also for skin resurfacing [2]. Skin resurfacing with lasers is indicated for dark circles due to skin laxity and tear trough. Lasers used for this purpose include the pulsed dye laser, diode laser and Nd: YAG lasers [4]. West and Alster [6] in a study of 20 patients comparing Q-switched alexandrite (755-nm) and Nd:YAG $(1,064-\mathrm{nm})$ lasers in the treatment of infraorbital dark circles, reported that both lasers were capable of lightening hyperpigmentation, with some improvement seen after the first treatment and even more fading noted after the second laser treatment. This study revealed no significant clinical difference between the two pigment specific laser systems.

Lowe and Colleagues [5], in a study of 17 patients with dermal infraorbital melanin deposition treated using a Q-switched ruby laser (694-nm), demonstrated a lightening response of greater than $50 \%$ in $23.5 \%$ of patients after one laser treatment and in $88.9 \%$ of patients after two treatments with post-treatment histology demonstrated a reduction in dermal melanin deposition. 
High-energy, pulsed $\mathrm{CO}_{2}$ laser, which is a nonpigment specific laser system, also showed successful results for the treatment of infraorbital dark circles. In these cases, dark circles were due to skin laxity and the beneficial effects were due to the ability to tighten dermal tissue and improve surface texture by vaporizing intracellular water [6].

Soft tissue fillers can be considered as an alternative treatment option. Goldberg and Fiaschetti [16]. Reported that patients who were unhappy with soft tissue filler injection to the periorbital area tended to have thinner skin, which is more vulnerable to developing increased vascularity and bruising. Lumps or contour irregularities are also common complications of soft tissue fillers, especially for thin eyelid skin.

Fat transplantation has been used in a variety of conditions involving volume loss. It is widely used for panfacial global subcutaneous atrophy secondary to intrinsic ageing or trauma [17]. Pinski and Roenigk reported that the mobility of the site being treated is one of the most important factors in determining the longterm survival of transplanted fat. The infraorbital area is a relatively non mobile area, which resulted in good survival of the transplanted fat [8].

Roh et al., [4] treated ten patients with dark circles due to increased vascularity and translucency of the skin using at least one autologous fat transplantation and follow-up evaluations were conducted at least 3 months after the last treatment. The authors concluded that autologous fat transplantation is an effective method for the treatment of infraorbital dark circles due to thin and translucent lower eyelid skin overlying the orbicularis oculi muscle.

According to Tonnard's study [10], mechanically processing fat completely disrupts the adipose tissue structure and produces nanofat with more regular and finer particles of fat than micro-fat. Thus, grafting with nanofat usually does not have a prominent direct volume-adding effect. Instead, the major effect of nanofat injection appears to relate to stem cell activity.

The nano-fat grafting technique introduced by Tonnard uses a very thin $27 \mathrm{G}$ injection needle for intradermal and subdermal injection. While in Dong $\mathrm{S}$ et al., study [12], blunt $20 \mathrm{G}$ cannula was used for nanofat injection in combination with micro-fat grafting sub-dermally. In the current study, the traditional $27 \mathrm{G}$ needle mounted on $1 \mathrm{ml}$ syringe was used for nanofat injection in the first five cases (50\%), but sometimes, resistance during injection was and obstacle using that technique, also, disconnection between the needle and the syringe leading to spoilage of the nano aspirate which makes injection difficult. Another problem we faced in that technique was the short length of the needle which required multiple punctures, so we shifted to use the long and thin $27 \mathrm{G}$ needle mounted on the metal dental syringe which is commonly used for dental anesthesia in the other five cases (50\%) Fig. (5). This was reflected in the marked reduction of the post-operative edema and ecchymosis seen in these cases.

In the current study, post-operative edema and ecchymosis were minimal in 5 cases $(50 \%)$. and mild in 5 cases $(50 \%)$. Four out of 5 cases $(80 \%)$ with minimal edema and ecchymosis were injected with dental needle, in addition, the dental needle provided a secured and controlled injection through the metal syringe without any risk of disconnection or spoilage of the aspirate.

All our patients were females, and the majority of them $(50 \%)$ were between 30 to 40 years this may be attributed to the fact that females seeks for treatment of dark halos than males in our community especially in this particular age group.

In the current study, fat harvesting site was chosen according to ease of accessibility and to improve the patient's body contours. Lower abdomen was the most accessible site in 4 cases (40\%) this may be attributed to the combination of liposuction to the abdominoplasties done to those patients.

There were neither major nor minor early postoperative complications in the current study; no cases were presented with infection this may be due to the complete aseptic technique followed during injection, in addition, all patients were instructed to gently apply fucidic acid ointment on the injected area three times daily for five days.

In the current study, there was significant clinical improvement of the periocular dark halos in 5 cases $(50 \%)$, moderate improvement was encountered in 2 cases $(20 \%)$, and two case $(20 \%)$ show mild improvement and no change in the colour was noted in only one case (10\%). There was good agreement about the clinical outcome between the two evaluating surgeons who were blind to the used technique. In this study, despite the wide range of objective improvement (no improvement, mild, moderate and significant), 8 cases $(80 \%)$ 
were satisfied with the final result and 2 cases $(20 \%)$ were not satisfied.

Unlike microfat grafting, which is complicated in some cases by postoperative irregularities of the eyelid skin, there were no case complained of any lumps or even irregularities. In addition, there was an obvious clinical improvement in the skin quality in all cases, our results suggest that the stem cell activity of the nanofat grafting technique has great potential as a treatment modality for skin rejuvenation in general, not only for the treatment of dark circles.

\section{Conclusion:}

This simple, cost effective procedure seems to be suitable for the correction of infraorbital dark circles, moreover, the stem cell activity of the nanofat grafting technique is a good tool for skin rejuvenation in general, not only for the treatment of dark circles. Further studies combining nanofat grafting with other treatment modalities are suggested for better improvement. Also histopathological studies have to be performed to find the exact rejuvenating effect of nanofat grafting.

\section{REFERENCES}

1- Yaar M. and Gilchrest B.A.: Skin aging: Postulated mechanisms and consequent changes in structure and function. Clin. Geriatr. Med., 17: 617-30, 2001.

2- Watanabe S., Nakai K. and Ohnishi T.: Condition known as "dark rings under the eyes" in the Japanese population is a kind of dermal melanocytosis which can be successfully treated by Q-switched ruby laser. Dermatol. Surg., 32: 785-9, 2006.

3- Epstein J.S.: Management of infraorbital dark circles. A significant cosmetic concern. Arch. Facial. Plast. Surg., 1: 303-7, 1999.

4- Roh M.R. and Chung K.Y.: Infraorbital dark circles: Definition, causes, and treatment options. Dermatol. Surg., 35: 1163-71, 2009 .
5- Lowe N.J., Wieder J.M., Shorr N., et al.: Infraorbital pigmented skin. Preliminary observations of laser therapy. Dermatol. Surg., 21: 767-70, 1995.

6- West T.B. and Alster T.S.: Improvement of infraorbital hyperpigmentation following carbon dioxide laser resurfacing. Dermatol. Sur., 24: 615-6, 1998.

7- Manuskiatti W., Fitzpatrick R.E. and Goldman M.P.: Treatment of facial skin using combinations of $\mathrm{CO}_{2}$, Qswitched alexandrite, flashlamp-pumped pulsed dye, and Er: YAG lasers in the same treatment session. Dermatol. Surg., 26: 114-20, 2000.

8- Pinski K.S. and Roenigk H.H. Jr.: Autologous fat transplantation. Longterm follow-up. J. Dermatol. Surg. Oncol., 18: 179-84, 1992.

9- Rho M.R., Kim T.K. and Chung K.Y.: Treatment of infraorbital dark circles by autologous fat transplantation: A pilot study. Br. J. Dermatol., 160: 1022-5, 2009.

10- Tonnard P., Verpaele A., Peeters G., Hamdi M., Cornelissen M. and Declercq H.: Nanofat grafting: Basic research and clinical applications. Plast. Reconstr. Surg., 132: 1017 26, 2013.

11- Charles-De-Sá L., Gontijo-De-Amorim N.F., MaedaTakiya C., Borojevic R., Benati D., Bernardi P., Sbarbati A. and Rigotti G.: Antiaging treatment of the facial skin by fat graft and adipose-derived stem cells. Plast. Reconstr. Surg., 135: 999-1009, 2015.

12- Dong Seok O.h.1, Dae Hwa Kim2, Tai Suk Roh3, In Sik Yun3 and Young Seok Kim: Correction of Dark Coloration of the Lower Eyelid Skin with Nanofat Grafting Arch. Aesthetic Plast. Surg., 20 (2): 92-6, 2014.

13- Chance E.W.: Treatment of unwanted pigment. Facial Plast. Surg., 30: 16-25, 2014.

14- Rendon M., Cardona L.M., Bussear E.W., et al.: Successful treatment of moderate to severe melasma with triplecombination cream and glycolic acid peels: A pilot study. Cuti., 82: 372-8, 2008.

15- Vavouli C., Katsambas A., Gregoriou S., et al.: Chemical peeling with trichloroacetic acid and lactic acid for infraorbital dark circles. J. Cosmet. Dermatol., 12 (3): 2049, 2013.

16- Goldberg R.A. and Fiaschetti D.: Filling the periorbital hollows with hyaluronic acid gel: Initial experience with 244 injections. Ophthal. Plast. Reconstr. Surg., 22: 335$41,2006$. 